Purdue University

Purdue e-Pubs

2006

\title{
Experimental Investigation of a Miniature-Scale Refrigeration System for Electronics Cooling
}

S. Trutassanawin

Purdue University - Main Campus

E. A. Groll

Purdue University - Main Campus

S V. Garimella

Purdue University, sureshg@purdue.edu

L Cremaschi

Purdue University - Main Campus

Follow this and additional works at: http://docs.lib.purdue.edu/coolingpubs

Trutassanawin, S.; Groll, E. A.; Garimella, S V.; and Cremaschi, L, "Experimental Investigation of a Miniature-Scale Refrigeration System for Electronics Cooling" (2006). CTRC Research Publications. Paper 135.

http://dx.doi.org/10.1109/TCAPT.2006.881762

This document has been made available through Purdue e-Pubs, a service of the Purdue University Libraries. Please contact epubs@purdue.edu for additional information. 


\title{
Experimental Investigation of a Miniature-Scale Refrigeration System for Electronics Cooling
}

\author{
Suwat Trutassanawin, Eckhard A. Groll ${ }^{\mathrm{ii}}$, Suresh V. Garimella, and Lorenzo Cremaschi \\ Ray W. Herrick Laboratories and Cooling Technologies Research Center \\ School of Mechanical Engineering, Purdue University \\ West Lafayette, Indiana 47907
}

\begin{abstract}
A miniature-scale refrigeration system suitable for electronics cooling applications was developed and experimentally investigated. A detailed review of the literature on refrigeration systems and system simulation models for application to electronics cooling is also provided. Experimental results obtained with the prototype system demonstrate its feasibility for use in cooling compact electronic devices. The cooling capacity of the system investigated varied from 121 to $268 \mathrm{~W}$, with a COP of 2.8 to 4.7 , at pressure ratios of 1.9 to 3.2. The effectiveness of the condenser ranged from 59 to $77 \%$, while a thermal resistance of 0.60 and $0.77{ }^{\circ} \mathrm{C}-\mathrm{cm}^{2} / \mathrm{W}$ was achieved at the evaporator. The evaporator-heat spreader thermal resistance is defined as the ratio of the temperature difference between the chip surface and the refrigerant evaporator to the evaporator heat transfer rate. The overall system thermal resistance, defined as the ratio of the temperature difference between the chip surface and the condenser air inlet, is of 0.04 to $0.18^{\circ} \mathrm{C}-\mathrm{cm}^{2} / \mathrm{W}$. An overall second-law efficiency ranging from 33 and $52 \%$ was obtained, using a commercially available small-scale compressor. The measured overall isentropic efficiency was between 40 and $60 \%$.
\end{abstract}

Index Terms-Miniature-scale refrigeration system, electronics cooling, small-scale compressor, second-law efficiency, coefficient of performance

\footnotetext{
${ }^{\mathrm{i}}$ Submitted for publication in IEEE Transaction on Components and Packaging Technologies, January 2005, and in revised form, February 2006.

ii Author to whom correspondence should be addressed: groll@ purdue.edu
} 


\section{Nomenclature}

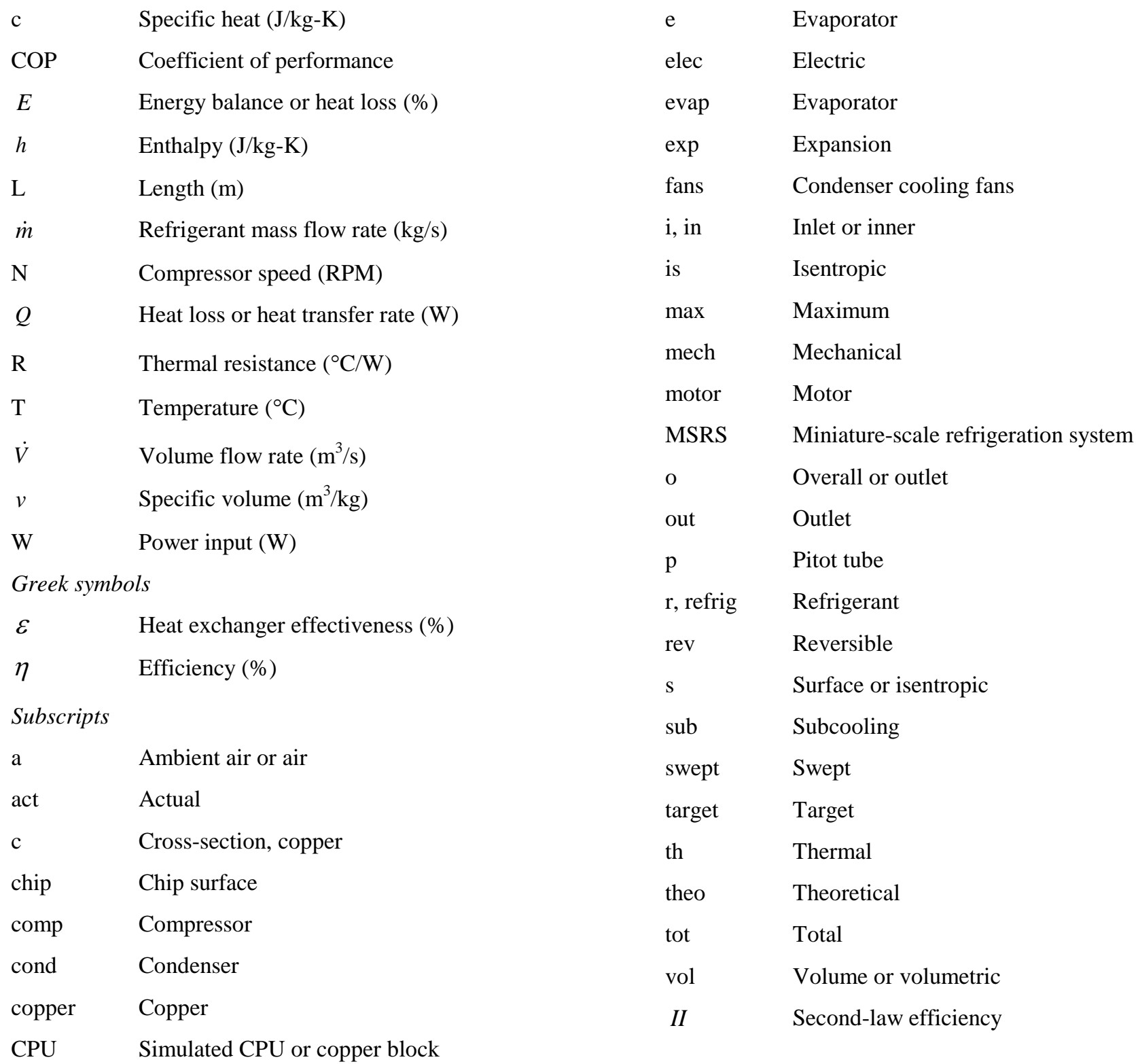

\section{Introduction}

As the number of transistors in integrated circuits has rapidly increased to provide greater functionality and computational power, removing the heat dissipated from electronic chips has become a serious challenge in the design of portable and other space-limited electronics devices. According to the International Technology Roadmap for Semiconductors 2003 [1], the heat dissipation from a single chip package will rise to $170 \mathrm{~W}$ in 2005 for high-performance systems. The maximum junction temperature, meanwhile, must continue to be maintained at or below $85^{\circ} \mathrm{C}$. Conventional air cooling techniques are no longer expected to meet the required heat dissipation needs. A host of alternative cooling approaches have been studied in the literature 
to achieve the required dissipation rates, while satisfying the required reliability and cost considerations; these methods include heat pipes, liquid immersion, jet impingement and sprays, thermoelectrics, and refrigeration.

Of the available alternatives, refrigeration is one of the only methods which can work in high-temperature ambients, and even result in negative values of thermal resistance. The advantages of refrigeration cooling [2] include maintenance of low junction temperatures while dissipating high heat fluxes, potential increases in microprocessor performance at lower operating temperatures, and increased chip reliability. However, these advantages must be balanced against the increased complexity and cost of the cooling system, possible increases in cooling system volume, and uncertainties in the system reliability due, for instance, to moving parts in the compressor.

The present work aims to further explore the advantages of refrigeration cooling, and investigate the feasibility of the use of this approach in electronics cooling. Studies of vapor compression systems and system simulation models in the literature directed at electronics cooling are first reviewed. Additional details regarding past work, as well as on commercially available systems, are available in Trutassanawin and Groll [3].

\section{Literature Review}

Scott [4] classified refrigerated cooling of electronic equipment into four major categories: refrigerated cooling of air or liquid, refrigerated heat sinks, liquid nitrogen baths, and thermoelectric coolers. The key difference between the first two of these is that a refrigerated heat sink results in a lower temperature at the surface of the chip compared to a refrigerated system using a cooling fluid, since it avoids use of a secondary fluid loop to carry heat from the chip to the refrigeration loop. In addition, the evaporator of the refrigerated heat sink is mounted directly to the chip leading to greater compactness. A liquid nitrogen bath may be used for cryogenic applications; its efficiency decreases significantly in the temperature range typical of electronics cooling. The liquid nitrogen bath is a batch-cooling mode operation and liquid nitrogen needs to be provided from an external cryogenic refrigeration system. The need for insulation of the bath and other implementation difficulties renders this approach impractical for electronics applications. Thermoelectric cooling has the advantage of no moving parts and compact size, but suffers from small cooling capacity, low temperature lift, and low efficiency. The efficiency of the overall thermoelectric system, which requires multiple stacked elements to achieve the desired cooling capacities, is low.

A number of refrigeration cooling systems for electronics are commercially available. Schmidt and Notohardjono [5] used a vapor-compression refrigeration system to cool the processor (a multi-chip module) in the IBM S/390 G4 CMOS server system, which was the first IBM system to employ refrigeration cooling: all other components of the server were air-cooled. Two modular refrigeration units (MRUs) were connected to the evaporator, with one of these serving as a backup. The size of the cooling unit was $267 \times 267 \times 711 \mathrm{~mm}^{3}$, with a weight of $27 \mathrm{~kg}$. The average processor temperature for the G4 server was 
maintained at $40^{\circ} \mathrm{C}$, which was approximately $35^{\circ} \mathrm{C}$ lower than the temperature that could be achieved with a conventional air cooling design.

Peeples [6] incorporated a vapor compression refrigeration system using refrigerant R-134a into an off-the-shelf high performance computer and developed a KryoTech super $\mathrm{G}^{\mathrm{TM}}$ computer. Advantages identified for sub-ambient cooling included faster switching of CMOS transistors, increased carrier mobility, improved sub-threshold operating characteristics and interconnect conductivity, and reduced junction leakage. However, one of the critical problems in this approach is moisture condensation on exposed surfaces at temperatures below the dew point of the surrounding air. Hence, any exposed cold surfaces must be insulated and sealed. Peeples identified the bulk and weight of the compressor, as well as a lack of robust interactive capacity control, as the reasons limiting widespread acceptance of refrigeration cooling for electronics.

Maveety et al. [7] developed a miniature-scale R-134a refrigeration system to fit into a 2-U rack with a cooling capacity of 130 $\mathrm{W}$, to achieve an integrated heat spreader temperature of $20^{\circ} \mathrm{C}$. The system was composed of a copper cold plate, a rotary compressor, an aluminum microchannel condenser with two $80 \mathrm{~mm} \times 80 \mathrm{~mm}$ axial fans, and a capillary tube. The overall system dimensions were $407 \mathrm{~mm} \times 178 \mathrm{~mm} \times 64 \mathrm{~mm}$. A variable-speed, brushless 24 volt DC rotary compressor, with a height of 89 $\mathrm{mm}$ and a $64 \mathrm{~mm}$ diameter was used in this system. The compressor had a displacement volume of $18 \mathrm{~mm}^{3}$, weighed $1.36 \mathrm{~kg}$, and used polyolester oil as the lubricant. The evaporation temperatures ranged from 5 to $20^{\circ} \mathrm{C}$, the ambient air temperatures varied between 25 and $35^{\circ} \mathrm{C}$, the working pressure ratio ranged from 3.1 to 3.6 , the compressor power consumption varied between 7 and $22 \mathrm{~W}$, and the COP ranged from 2.2 to 5.8. The junction to ambient air thermal resistance of the system decreased from -0.012 to $-0.13^{\circ} \mathrm{C} / \mathrm{W}$ as the condenser air flow rate was increased from 0.01 to $0.015 \mathrm{~kg} / \mathrm{s}$.

A mesoscale vapor-compression refrigerator was analyzed in Phelan and Swanson [8], with the term mesoscale denoting a system of $5 \mathrm{~cm}^{3}$ in total volume or smaller. Different refrigerants were considered in an effort to maximize the COP. Ammonia was found to be the best refrigerant due to its larger latent heat compared to R-22 and R-134a. For the system size considered, a very small charge of ammonia would be needed. Using a simple thermodynamic model to analyze five types of compressors (reciprocating, screw, rotary, scroll, and centrifugal), a scroll compressor was suggested for the application because of its high isentropic and volumetric efficiencies. The study also pointed to the need for further studies on small-scale compressors.

Suman et al. [9] used a simple thermal resistance correlation to compare different cryogenic cooling technologies for electronics: a Linde air cycle, a Stirling cycle, a vapor compression refrigeration (VCR) cycle, a cascaded vapor compression refrigeration cycle, a vortex tube, and a liquid nitrogen system. The thermal resistance equation showed that the coefficient of performance (COP) of the vapor compression refrigeration cycle decreased with a decrease in junction temperature. Liquid nitrogen was claimed to be a suitable approach for cryogenic cooling of electronics. 
There appear to be only two studies in the literature which report on refrigeration system models for electronics cooling. Neither model included an analysis of the heat spreader and the chip package. Bash [10] developed a vapor-compression system model for an ideal small-scale refrigeration cycle to be used in electronics cooling applications. A conventional vapor compression system, consisting of a serpentine evaporator, an intercooler, a compressor, a plate fin-and-tube condenser, and a capillary tube expansion device, was also tested. An alternative hot-gas bypass valve, from the compressor outlet to the evaporator inlet, was used to control the refrigerant flow to the evaporator and to control the evaporator capacity. The hot-gas bypass valve also served to prevent condensation of moisture in the air on the evaporator surface if its temperature dropped below the dew point. Bash's model assumed an isenthalpic process through the expansion device, and did not include the refrigerant pressure drop in the evaporator or in the condenser; the air-side pressure drop across the condenser was similarly not considered. Analysis of refrigeration inventory or of the chip package was also not included. A refrigeration test setup with a $400 \mathrm{~W}$ heat load at $25^{\circ} \mathrm{C}$ was built. Limited experimental tests were presented at a constant condenser air flow rate of $0.031 \mathrm{~m}^{3} / \mathrm{s}(65 \mathrm{CFM})$ and evaporator temperature of $20^{\circ} \mathrm{C}$. The model was validated against the test results: the accuracy of the pressure and temperature predictions was within $\pm 10 \%$ and the accuracy of the COP predictions was within $\pm 8 \%$ for heat loads between 210 and $400 \mathrm{~W}$.

A system model was developed by Heydari [11] for a miniature refrigeration system consisting of a free-piston linear compressor, a condenser, a capillary tube, and a cold plate evaporator. Available thermodynamic models [12] for the different systems components, including the condenser [13], evaporator [14], and capillary tube [15] were employed. The model included empirical correlations for computing refrigerant-side pressure drops in both the evaporator and condenser. The model also predicted the mass flow rate of the expansion device, and calculated refrigerant charge inventory. Determination of the air-side performance and pressure drop were not included, and the model results were not validated against experiments. Compressor reliability was identified as the critical component of the cooling system.

It is clear from the literature review that miniature-scale refrigeration systems for electronics cooling have not been widely studied, especially by means of experimental investigations. There is also a lack of information regarding the performance of individual components as well as a careful analysis of the energy loss in small refrigeration systems for electronics cooling applications. The present experimental investigation involves the design, construction, and testing of a miniature-scale refrigeration system (MSRS) for electronics cooling, as described below. An analysis of the results is undertaken to identify the irreversibility and performance of the individual components as well as to demonstrate the performance of the small-scale refrigeration system for electronics cooling applications. 


\section{Present Work}

A miniature-scale refrigeration system [8], with the term miniature-scale denoting a system in which the heat exchangers have a maximum height of $45 \mathrm{~mm}\left(1-\mathrm{U}\right.$ rack) and the compressor has a maximum volume of $1000 \mathrm{~cm}^{3}$, has been designed, constructed and tested. The components of the miniature-scale refrigeration system were prototyped and/or selected from commercially available components to fit into the space available in a personal computer. Detailed experimental measurements were obtained which enable the estimation of component performances and system behavior over a wide range of operating conditions. Quantification of the energy losses in the refrigeration system is a key contribution of this work. In addition, while most previous studies have considered ideal vapor compression cycles, the current work presents a more general and comprehensive thermodynamic analysis of the actual refrigeration system for electronics cooling and accounts for the main energy losses in the system. Each component of the system is analyzed to provide better physical insights into the system performance.

\section{A. Experimental System}

A schematic of the miniature-scale refrigeration system (MSRS) for electronics cooling is shown in Fig.1. The system consists of the following components: a commercially available small-scale compressor, a microchannel condenser, a manual needle valve as the expansion device, a cold plate microchannel evaporator, a heat spreader, two compressor cooling fans, and a heat source which simulates the chip. In addition, a suction line accumulator was installed in the system to guarantee that only refrigerant vapor flows into the compressor. An oil filter and a sight glass were used to provide the required compressor lubrication and to verify refrigerant subcooling at the condenser outlet. A photograph of the bread board system is shown in Fig. 2 while Fig. 3 shows the components of the miniature-scale refrigeration system for electronics cooling used during the experiments.

A commercially available small-scale hermetic R-134a rotary compressor (Hitachi Model XL0623D1, $8.5 \mathrm{~cm}$ in diameter and $16.6 \mathrm{~cm}$ in height), was used to compress the refrigerant. The compressor is driven by a DC brushless motor and its design operating conditions are an ambient temperature of $55^{\circ} \mathrm{C}$, a suction gas temperature of $32^{\circ} \mathrm{C}$, and a liquid temperature at the condenser outlet of $32^{\circ} \mathrm{C}$. The compressor design cooling capacity varies from 75 to $140 \mathrm{~W}$, the COP varies from 1.13 to 1.35 , and the maximum power consumption is approximately $103 \mathrm{~W}$ at typical portable refrigerator operating conditions. The rotary compressor is a variable-speed compressor with DC $12.8 \mathrm{~V} / 25.6 \mathrm{~V}$ power input and includes an inverter to change the voltage from DC to 3-phase AC. The compressor speed can be varied in the range from 2000 to 3500 RPM. The swept (displaced) volume of the compressor during each stroke is $2.3 \mathrm{~cm}^{3} /$ revolution.

The heat source consists of a cubical copper block with dimensions of $19 \mathrm{~mm}$ on a side. Two cartridge heaters mounted into the base underneath the copper block and controlled with input from a variable transformer provide up to $400 \mathrm{~W}$ of input power. The copper block-heat spreader-evaporator interfaces were improved with a thermally conductive paste. The evaporator is an 
aluminum microchannel heat exchanger, (Lytron Model CP20G01), which consists of 41 rectangular channels, each of cross section $0.8 \mathrm{~mm} \times 2.3 \mathrm{~mm}$. The expansion device is a hand-operated needle valve. A prototype microchannel condenser (from Modine Manufacturing Co.) was used in the experimental test set up. The condenser has a heat rejection capacity of $225 \mathrm{~W}$ and dimensions $45 \mathrm{~mm} \times 180 \mathrm{~mm} \times 25 \mathrm{~mm}$, which are consistent with the dimensions of a 1-U rack of desktop computer. It has 20 rectangular microchannels of dimensions $0.62 \mathrm{~mm} \times 0.33 \mathrm{~mm}$. Four DC $24 \mathrm{~V}$ fans provide a maximum flow rate of $0 . .027 \mathrm{~m}^{3} / \mathrm{s}$ (about $57 \mathrm{CFM}$ ). Each fan has dimensions of $40 \mathrm{~mm} \times 40 \mathrm{~mm} \times 25 \mathrm{~mm}$ and requires a power input of $3.6 \mathrm{~W}$. The four fans were installed downstream of the heat exchanger to guarantee sufficient air flow rate across the condenser inside the long wind tunnel

used in the experimental setup. A resistance heater was also installed at the inlet of the air duct to control the inlet air temperature. During the experiments, the condenser inlet air temperature was set at 25,27 , or $35^{\circ} \mathrm{C}$. The refrigerant pipe, air duct, and heater block were well insulated to reduce heat losses to the ambient air. The MSRS was charged with $100 \mathrm{~g}$ of the refrigerant $\mathrm{R}-134 \mathrm{a}$.

Thermocouples and pressure transducers were installed on the refrigerant-side at the inlet and outlet of the compressor, condenser, expansion device, and evaporator to determine the refrigerant state points. The refrigerant mass flow rate was measured using a Coriolis-effect mass flow meter installed between the outlet of the condenser and the expansion device. The mass flow meter (model D6S-SS from Micro Motion) had a range of 0 to $16 \mathrm{~g} / \mathrm{s}$. The power input to the cartridge heaters in the copper block was measured by an $\mathrm{AC}$ power meter, while the heat input to the evaporator was determined from a row of two thermocouples installed in the copper block in the direction of heat flow as shown in Fig. 4. Since the compressor needed an inverter to change the power input from DC to 3-phase AC voltage, the power meter was installed after the inverter to measure directly the actual electrical power required by the compressor, $\mathrm{W}_{\text {comp, elec. }}$ On the air-side, six thermocouples were uniformly distributed at the inlet and six at the outlet of the condenser. The air flow rate over the condenser was measured using a Pitot tube installed inside the air duct according to ANSI/ASHRAE Standard 41.2-1987 [16]. Six thermocouples were also installed at the Pitot tube location to obtain an average temperature for calculating the air density.

\section{B. Data Reduction}

The heat dissipation rate from the simulated electronic chip to the evaporator was measured from the heat conduction in the copper block according to (1):

$$
Q_{C P U}=\frac{k_{c o p p e r} A_{c}}{L_{c 1-c 3}}\left(T_{c 3}-T_{c 1}\right)
$$

where, $T_{c 1}$ and $T_{c 3}$ are the temperatures at the top and bottom positions of the copper block, and $L_{c 1-c 3}$ is the distance between the two thermocouples as shown in Fig. 4. 
The cooling capacity of the refrigeration system was calculated by multiplying the refrigerant mass flow rate with the refrigerant enthalpy difference across the evaporator:

$$
Q_{\text {evap }, r}=\dot{m}_{r}\left(h_{\text {evap }, o}-h_{\text {evap }, i}\right)
$$

From the measurement of the refrigerant outlet pressure and temperature in the single-phase superheat region, the outlet evaporator enthalpy was computed using Engineering Equation Solver (EES) [17]. The evaporator inlet enthalpy was obtained by assuming an isenthalpic process across the expansion device. The inlet enthalpy of the expansion device was computed using EES from the measurement of the pressure and temperature in the single-phase subcooled region. The energy balance of the evaporator was computed as the ratio of the difference between the heat input from the CPU and the refrigerant cooling capacity, to the CPU heat input:

$$
E_{\text {evap }}=\frac{100\left(Q_{C P U}-Q_{\text {evap }, r}\right)}{Q_{C P U}}
$$

Ideally, the evaporator energy balance would be zero. However, due to uncertainties in the measurements and heat losses, the energy balance differed from zero in some cases. Only experimental test runs that resulted in evaporator energy balances of $\pm 15 \%$ were considered valid. The refrigerant heat rejection at the condenser is calculated in a manner analogous to that of the evaporator heat input.

The air-side heat rejection at the condenser was determined as the product of the air volume flow rate measured by the Pitot tube, the air density at the inlet to the Pitot tube based on measurements of temperature, humidity and pressure, and the air-side enthalpy difference across the condenser based on measurements of temperature, humidity and pressure:

$$
Q_{\text {cond }, a}=V_{a} \rho_{a}\left(h_{\text {cond }, \text { air }, o}-h_{\text {cond }, \text { air }, i}\right)
$$

The energy balance for the condenser was calculated in a manner analogous to that for the evaporator, as the ratio of the difference between the refrigerant-side and air-side heat rejection rates to the refrigerant-side heat rejection rate. Ideally, the condenser energy balance would be zero as well. However, due to uncertainties in the measurements and heat losses, the energy balance differed from zero in some cases. Only experimental test runs that resulted in condenser energy balances of $\pm 10 \%$ were considered valid.

The performance of the system was characterized by the COP of the refrigeration cycle and the COP of the overall system according to the following definitions:

$$
C O P_{\text {refrig }}=\frac{Q_{\text {evap }, r}}{W_{\text {comp }, \text { refrig }}}
$$




$$
C O P_{M S R S}=\frac{Q_{\text {evap }, r}}{W_{\text {elec }}}
$$

where the overall system work, $W_{\text {elec }}$, includes the power consumption of the compressor, condenser fans, and compressor cooling fans.

The experimental results to be presented indicate that the compressor used in the experiments did not perform at high efficiencies. If a typical high efficiency compressor were employed in this application, the power input of the compressor could be reduced. Therefore, a target total power consumption is introduced which is dependent on the compressor's overall isentropic efficiency and the electrical power consumption of the fans:

$$
W_{\text {target }, \text { tot }}=\frac{W_{\text {comp }, \text { refrig }}}{\eta_{o, \text { is }}}+W_{\text {cond }, \text { fans }}+W_{\text {comp }, \text { fans }}
$$

The overall isentropic efficiency of the compressor is defined as:

$$
\eta_{o, i s}=\frac{\dot{m}_{r}\left(h_{\text {comp }, o s}-h_{\text {comp }, i}\right)}{W_{\text {elec }}}
$$

The overall compressor isentropic efficiency summarizes the effects of the isentropic and mechanical efficiencies, as well as the motor efficiency:

$$
\eta_{o, i s}=\eta_{i s} \eta_{\text {mech }} \eta_{\text {motor }}
$$

The volumetric efficiency can be computed from the measured refrigerant mass flow rate, compressor speed, and swept volume as:

$$
\eta_{v o l}=\frac{\dot{m}_{r, a c t}}{\dot{m}_{r, \text { theo }}}=\frac{\dot{m}_{r, a c t}}{\left(N \dot{V}_{\text {swept }}\right) /\left(60 v_{\text {comp }, i}\right)}
$$

By using a typical overall isentropic efficiency, a target COP was computed as the ratio of the refrigerant cooling capacity to the target total power consumption of (1) :

$$
C O P_{\text {target }}=\frac{Q_{\text {evap }, r}}{W_{\text {target,tot }}}
$$

The second-law efficiency of the refrigeration system can be expressed in terms of the actual coefficient of performance and the reversible coefficient of performance as:

$$
\eta_{I I, M S R S}=\frac{C O P_{M S R S}}{C O P_{r e v}}
$$

The reversible coefficient of performance is obtained from the Carnot refrigeration cycle applied to the actual evaporating and condenser temperatures: 


$$
C O P_{\text {rev }}=\frac{1}{T_{\text {cond }} / T_{\text {evap }}-1}
$$

in which both evaporator and condenser temperatures are in Kelvin.

The condenser effectiveness is the ratio between the air-side heat rejection rate and the maximum heat rejection rate of condenser:

$$
\varepsilon_{\text {cond }}=\frac{Q_{\text {cond }, a}}{Q_{\text {cond }, \max }}
$$

where the maximum heat rejection rate is the product of the minimum heat capacity and the maximum temperature difference. The latter was calculated as the difference between the saturated temperature of the refrigerant at the inlet pressure and the air temperature at the condenser inlet:

$$
Q_{\text {cond }, \max }=\dot{m}_{\text {air }} c_{\text {air }}\left(T_{\text {sat } @ P=P_{\text {cond }, i}}-T_{\text {air }, i}\right)
$$

For the evaporator, the general definition of heat exchanger effectiveness is not applicable because the heat exchange is not between two fluids. Therefore, the evaporator-heat spreader thermal resistance is used to characterize the evaporator:

$$
R_{\text {th,evap }}=\frac{T_{\text {chip }}-T_{\text {evap }}}{Q_{\text {evap }, r}}
$$

where $T_{c h i p}$ is the chip surface temperature (represented by $T_{c 0}$ in Fig. 4). The overall system thermal resistance is defined as the ratio of temperature difference between chip surface and condenser air inlet to the chip heat dissipation rate:

$$
R_{t h, s y s}=\frac{T_{c h i p}-T_{c o n d, a i r, i}}{Q_{C P U}}
$$

\section{Uncertainty Analysis}

The experimental measurements have the following accuracies: temperature $\pm 0.5^{\circ} \mathrm{C}$, refrigerant pressure $\pm 0.13 \%$ of transducer full scale ( 0 to $1724 \mathrm{kPa}$ and 0 to $3447 \mathrm{kPa}$ ), air differential pressure $\pm 1.0 \%$ of transducer full scale ( 0 to $125 \mathrm{~Pa}$ ), refrigerant mass flow rate $\pm 3.2 \%$ for mass flow rates of 0.5 to $3 \mathrm{~g} / \mathrm{s}$, compressor speed $\pm 2.5 \%$ for 2000 to $3500 \mathrm{RPM}$, and power $\pm 4.0 \%$ for power consumption of 0 to $400 \mathrm{~W}$. Using the equations presented in the previous section and by using EES [17], the error propagation was computed and the estimated uncertainties of the cooling capacity and system COP were $\pm 3.3 \%$ and $\pm 3.8 \%$, respectively. Furthermore, the uncertainties of the overall isentropic and volumetric efficiency of the compressor and of the second-law efficiency of the MSRS were $\pm 6.9 \%, \pm 4.7 \%$ and $\pm 7.0 \%$, respectively. The uncertainty of the condenser effectiveness, the evaporator-heat spreader thermal resistance, and the overall system thermal resistance were $\pm 8.5 \%, \pm 3.7 \%$ and $\pm 17.0 \%$, respectively. 


\section{Performance Results and Discussion}

System performance measurements were conducted under the following operating conditions: evaporator temperatures of 10 to $20^{\circ} \mathrm{C}$; refrigerant superheat at the compressor inlet of 3 to $8^{\circ} \mathrm{C}$; condenser temperature of 40 to $60^{\circ} \mathrm{C}$; refrigerant subcooling temperature at the condenser outlet of 3 to $10^{\circ} \mathrm{C}$; and ambient air temperatures of 25,27 , and $35^{\circ} \mathrm{C}$.

The energy balances of the condenser and the cold plate evaporator are illustrated in Fig. 5 and Fig. 6, respectively. The energy balance of the condenser was within $\pm 10 \%$. The discrepancy in the energy balance of the condenser was mostly due to inaccuracies in determining the air volume flow rates. The energy balance of the evaporator was within $\pm 15 \%$. In general, the measured refrigerant side cooling capacity was lower than the measured heat transfer rate from the CPU. The reasons for this consistent discrepancy include heat losses from the copper block/heat spreader through the insulation to the ambient air. Fluctuations in the discrepancies of the evaporator energy balances were due to measurement uncertainties.

The cooling capacity of the MSRS for different inlet air temperatures at two different condenser air flow rates is shown in Fig. 7. The evaporator heat transfer rate increases with increasing evaporator temperature, at fixed inlet air temperature and air flow rate. This is due to the lower pressure ratio and higher refrigerant mass flow rate. At a fixed inlet air temperature and constant evaporator temperature, the cooling capacity of the MSRS increases if the air flow rate increases, due to greater heat dissipation from the condenser. The system cooling capacity also increases if the condenser air inlet temperature decreases, probably because of the augmented refrigerant mass flow rate in the system, which leads to lower degrees of sub-cooling and superheat. However, the response of the system is such that the overall product of the refrigerant mass flow rate and the evaporator enthalpy difference increases at lower condenser air inlet temperatures. At a constant air flow rate of $30 \mathrm{CFM}$, the cooling capacity increases by $28 \%$ as the condenser air inlet temperature decreases from 35 to $25^{\circ} \mathrm{C}$. At a constant air flow rate of $22 \mathrm{CFM}$, the cooling capacity increases by $23 \%$ as the condenser air inlet temperature decreases from 35 to $27^{\circ} \mathrm{C}$.

The overall system performance strongly depends on the compressor efficiency. If the overall compressor isentropic efficiency decreases, the electric power consumption increases and thus, the COP decreases. The compressor used in the experiments was not designed for the given electronics cooling application, and its measured overall isentropic efficiency was only between 25 and 60\%. In general, overall isentropic compressor efficiencies between $50-70 \%$ can be achieved for small and medium-scale compressors of 3 to $10 \mathrm{~kW}$ cooling capacity [18]. It may be noted that with increasing time of compressor usage, both the measured overall isentropic and volumetric efficiencies decreased as shown in Fig. 8. By the time the compressor failed, these efficiencies decreased to values of $40 \%$ and $30 \%$, respectively. Clearly, a more reliable compressor is needed.

Figure 9 shows the variation in system $\mathrm{COP}$ as a function of the evaporator temperature at various condenser air inlet temperatures. At a given inlet air temperature, the system COP increases as the evaporator temperature increases, since the 
compressor power consumption decreases towards lower pressure ratios while the cooling capacity slightly increases. For instance, at an evaporator temperature of $20^{\circ} \mathrm{C}$, the system COP decreased by $20 \%$ as the inlet air temperature increases from 25 to $35^{\circ} \mathrm{C}$. Also shown in Fig. 9 is the target coefficient of performance calculated using (11) with an assumed higher compressor overall isentropic efficiency of $65 \%$, which shows the potential for improvement of COP with the use of an improved compressor. It can be seen from Fig. 9 that the measured system COP is already in close proximity to the target COP for several operating conditions. However, COP improvements of 5 to $18 \%$ can be reached if a well designed compressor is used. It is the main task of an ongoing research effort by the authors to develop compression concepts with an overall isentropic efficiency of 60 to $70 \%$ and that will fit into the maximum height of $45 \mathrm{~mm}$ (1-U rack) that is available in a personal computer.

The second-law efficiency of the system is illustrated in Fig. 10 as a function of the refrigerant evaporator temperature. The second-law efficiency, calculated from (12), ranged between 33 and 52\%. The irreversibilities in the compressor were the main losses and represented approximately half of the compressor power input. The compressor used in the experiments was oversized with respect to the rest of the system. Condenser irreversibility accounted for approximately $15 \%$ of the compressor power input, while the irreversibilities in the expansion device and evaporator were $5 \%$ and $2 \%$ of the compressor power input, respectively. At constant inlet air temperature, the second-law efficiency increases as the evaporator temperature increases. At the condenser air inlet temperature of $27^{\circ} \mathrm{C}$, the second-law efficiency increases by $11 \%$ as the refrigerant evaporator temperature increases from 9 to $20^{\circ} \mathrm{C}$.

The experimentally determined evaporator-heat spreader thermal resistance is shown in Fig. 11 . The resistance is seen to be in the range of 0.60 and $0.77^{\circ} \mathrm{C}-\mathrm{cm}^{2} / \mathrm{W}$ for temperature difference between chip surface and refrigerant evaporator of 27 to $54{ }^{\circ} \mathrm{C}$. The thermal resistance is essentially invariant with mass flow rate since the evaporator cooling capacity, evaporator temperature, and junction temperature increase with increasing mass flow rate. The thermal resistance can be further minimized by improving the interface contact conductances in the experimental system. The overall system thermal resistance is in the range 0.04 to 0.18 ${ }^{\circ} \mathrm{C}-\mathrm{cm}^{2} / \mathrm{W}$, as shown in Fig. 12.

The heat flux of the simulated CPU is shown as a function of the temperature difference between the chip surface and the evaporator in Fig. 13. The heat flux that could be sustained ranged from 36 to $76 \mathrm{~W} / \mathrm{cm}^{2}$, and increased linearly with the temperature difference between the chip surface and evaporator temperatures. Therefore, the junction to evaporator thermal resistance is invariant with the heat load of the processor.

Measurements from the present experiments also showed that the pressure ratio of the refrigeration system ranged from 1.9 to 3.2 as the refrigerant mass flow rate was varied from 0.8 to $1.7 \mathrm{~g} / \mathrm{s}$ depending on operating conditions. The surface temperature of the copper block that simulates the $\mathrm{CPU}$ ranged from 33.8 to $77.6^{\circ} \mathrm{C}$. The measured surface temperature is lower than the 
maximum allowed junction temperature of $85^{\circ} \mathrm{C}$ [1]. Therefore, the miniature-scale refrigeration system can handle high heat dissipation rates while maintaining the junction temperature at desirable levels. The most significant losses occurred in the compressor while the condenser and the evaporator performed to specification. Finally, the effectiveness of the condenser varied between 52 and $77 \%$ during the testing whereas the energy balance between the refrigerant and air sides is satisfied to within $\pm 10 \%$. This shows that the condenser performed to typical heat exchanger specifications.

\section{Conclusions}

A bread board miniature-scale vapor compression refrigeration system (MSRS) using R-134a as the refrigerant was designed, built, and tested. A commercially available small-scale compressor was installed in the MSRS. After an extensive experimental investigation, the main energy losses of the MSRS were highlighted. The most significant losses occurred in the compressor while the condenser and the evaporator performed to specification. A new compressor design for electronics cooling applications is needed to achieve better performance of the systems. The novel compressor has to fit within $45 \mathrm{~mm}$ height (1-U rack), has to be reliable, and needs to be inexpensive for mass production. The experimental results showed that the system was able to dissipate CPU heat fluxes of approximately $40-75 \mathrm{~W} / \mathrm{cm}^{2}$ and keep the junction temperature below $85^{\circ} \mathrm{C}$ for a chip size of 1.9 $\mathrm{cm}^{2}$. When a miniature-scale vapor compression system is used in electronics cooling applications, the efficiency and reliability of the compressor are the main challenges that need to be addressed. The compressor failed after 50 steady-state performance tests, which represent approximately 400 hours of operation. This was mainly due to the fact that the compressor was not designed for the operating conditions of electronics cooling. It was originally designed to run at much higher pressure ratios and much lower evaporator temperatures than those of the given application. Thus, overheating, re-expansion processes, and flow losses eventually occurred in the compressor during the experiments.

Reliability issues of miniaturized compressors need to be addressed in greater detail in future studies. Another recommended area of study is the development of an automatic expansion device and a suitable control strategy for MSRS. The automatic expansion device is needed to accurately control the expansion process, i.e., the mass flow rate through the expansion valve as a function of the heat load fluctuations of the microprocessor. The system control should prevent condensation at the evaporator by maintaining the refrigerant evaporator temperature slightly above the dew point temperature of the surrounding air.

\section{References}

[1] The International Technology Roadmap for Semiconductors, 2003 edition, Assembly and Packaging, Semiconductor Industry Association. 
[2] Phelan, P.E., 2001, Current and Future Miniature Refrigeration Cooling Technologies for High Power Microelectronics, Semiconductor Thermal Measurement and Management Symposium, San Jose, CA USA, March 20-22, 2001, pp. 158-167.

[3] Trutassanawin, S. and Groll, E.A., 2004, Review of Refrigeration Technologies for High Heat Dissipation Electronics Cooling, Proceedings of the International Refrigeration and Air Conditioning Conference, Purdue University, West Lafayette, Indiana, USA, July 12-15, 2004.

[4] Scott, A.W., 1974, Cooling of Electronic Equipment, John Wiley and Sons, pp. 204-227.

[5] Schmidt, R.R., and Notohardjono, B.D., 2002, High-End Server Low-Temperature Cooling, IBM Journal Research and Development, Vol. 46, pp. 739-751.

[6] Peeples, J.W., 2001, Vapor Compression Cooling for High Performance Applications, Electronics Cooling, Vol. 7, pp. 16-24.

[7] Maveety, J.G., et al., 2002, Thermal Management for Electronics Cooling Using a Miniature Compressor, International Microelectronics and Packaging Society (IMAPS), Denver, CO.

[8] Phelan, P.E. and Swanson, J., 2004, Designing a Mesoscale Vapor-Compression Refrigerator for Cooling High-Power Microelectronic, Inter Society Conference on Thermal \& Themomechanical Phenomena in Electronic Systems (I-THERM), Las Vegas, NV, June 1-4, 2004, pp. 218-223.

[9] Suman, S., Fedorov, A., and Joshi, Y., 2004, Cryogenic/Sub-Ambient Cooling of Electronics: Revisited, Inter Society Conference on Thermal \& Themomechanical Phenomena in Electronic Systems (I-THERM), Las Vegas, NV, June 1-4, 2004, pp. 224-231.

[10] Bash, C.E., 2001, Analysis of Refrigerated Loops for Electronics Cooling, Proceeding of IPACK'01, The Pacific Rim/ASME International Electronic Packaging Technical Conference and Exhibition, July 8-13, Kauai, Hawaii, pp. $811-819$

[11] Heydari, A., 2002, Miniature Vapor Compression Refrigeration Systems for Active Cooling of High Performance Computers, 8th Intersociety Conference on Thermal and Thermomechanical Phenomena in Electronic Systems (I-THERM), May 30 - June 1, 2002, pp. 371-378.

[12] Fischer, S.K., and Rice, C.K., 1983, The Oak Ridge Heat Pump Models 1: A Steady-State Computer Design Model of Airto-Air Heat Pumps, ORNL/COM-90/R1, Oak Ridge National Laboratory, Tennessee.

[13] Kempiak, M.J., Crawford, R.R., 1992, Three-zone, steady-state modeling of a mobile air-conditioning condenser, ASHRAE Transactions, Vol. 98, Part 1, pp. 475-488. 
[14] Domanski, A.P., 1991, Simulation of an evaporator with nonuniform one-dimensional air distribution, ASHRAE Transactions, Vol. 97, Part 1, pp. 793-802.

[15] Wolf, D.A., Bittle, R.R., and Pate, M.B., 1998, Generalized Performance Prediction Method for Adiabatic Capillary Tubes, HVAC\&R Research, Vol. 4, pp. 27-43.

[16] ANSI/ASHRAE 41.2-1987 (RA92) Standard, 1992, Standard Methods of Laboratory Airflow Measurement.

[17] Klein, S.A., 1992-2004, Engineering Equation Solver, EES, F-Chart Software, Madison, WI.

[18] Groll, E.A., and Braun, J.E., 2004, U.S. National Committee of the International Institute of Refrigeration Short Course on Simulation Tools for Vapor Compression Systems and Component Analysis, International Refrigeration and Air Conditioning Conference at Purdue University, July 10-11, 2004.

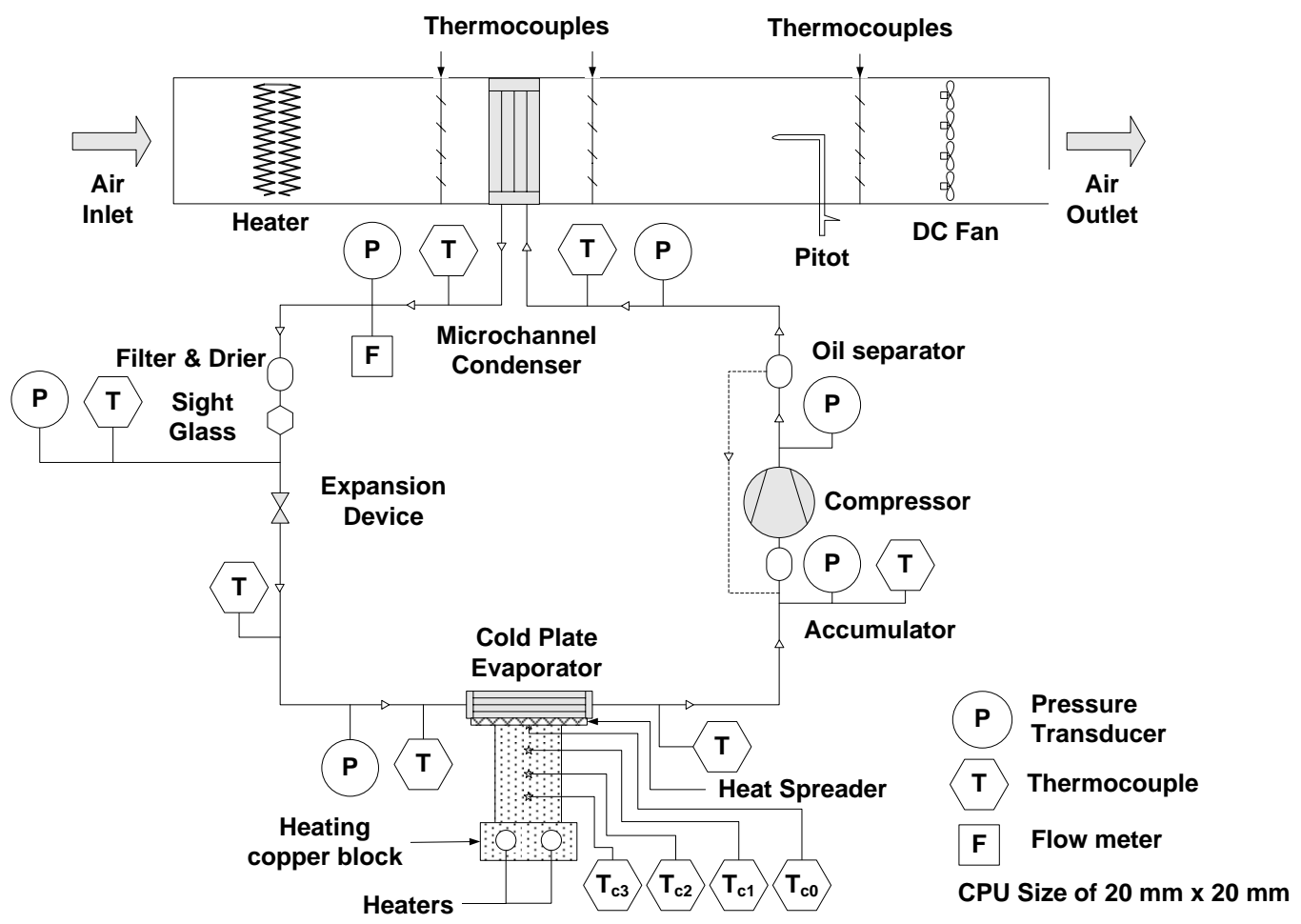

Fig. 1: Schematic of bread board miniature-scale refrigeration system. 


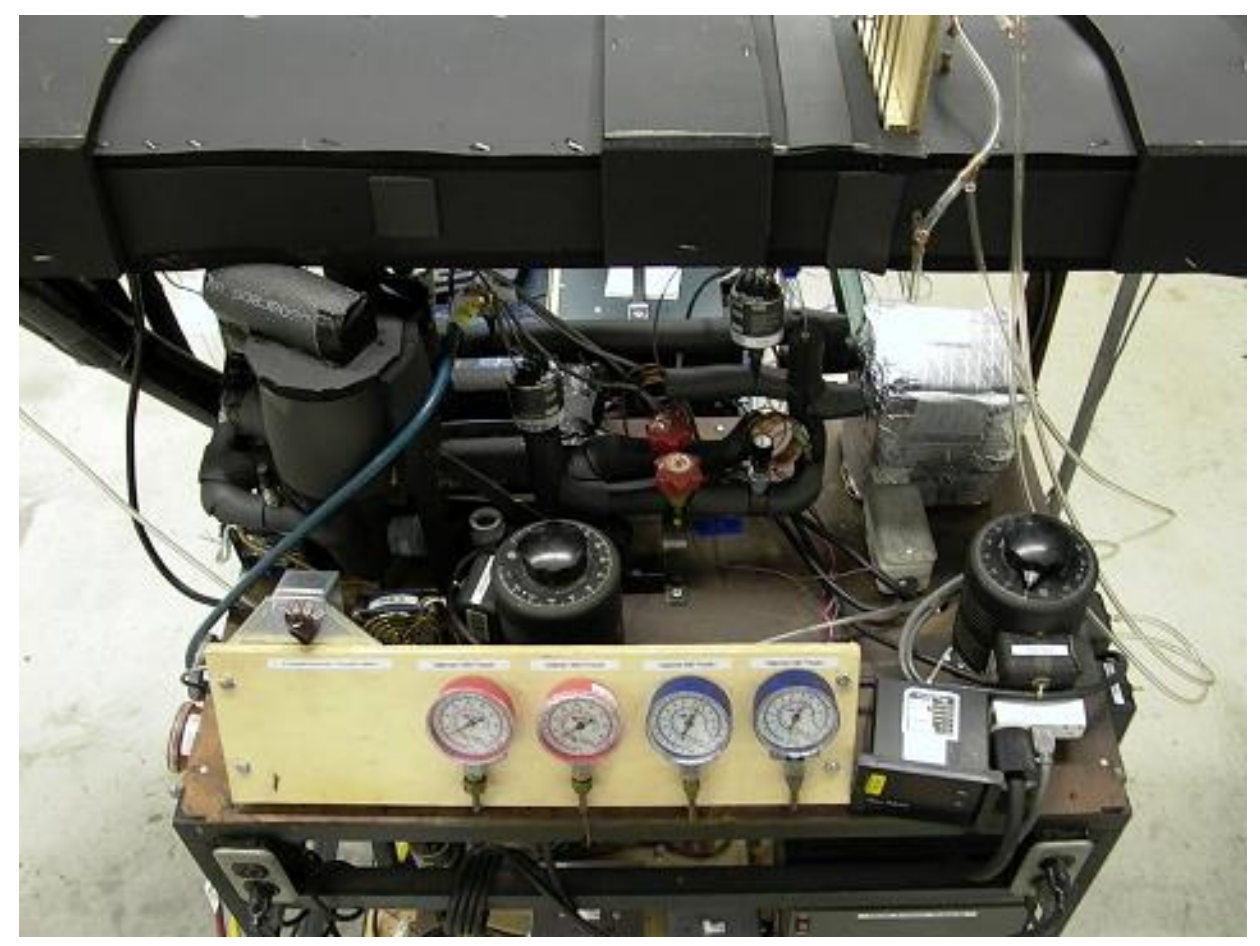

Fig. 2: Photograph of bread board miniature-scale refrigeration system for electronics cooling.

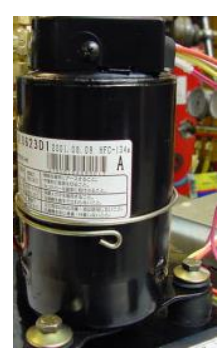

(a) Rotary compressor

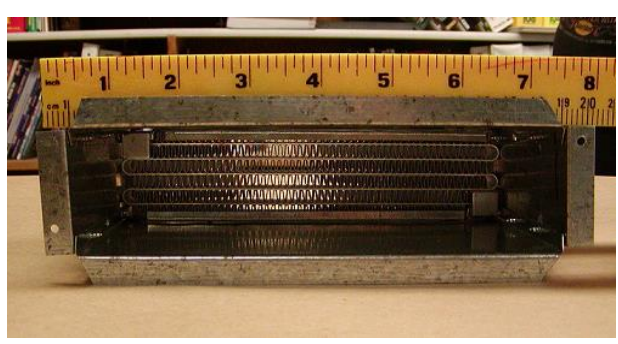

(b) Microchannel condenser

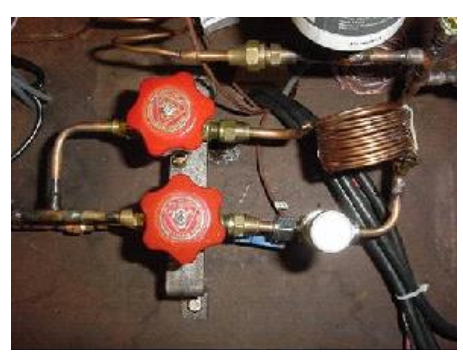

(c) Expansion device

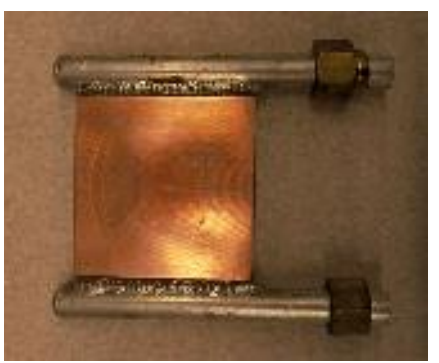

(d) Microchannel evaporator-heat spreader

Fig. 3: Photographs of components in the miniature-scale refrigeration system for electronics cooling. 


\section{Cold plate evaporator}

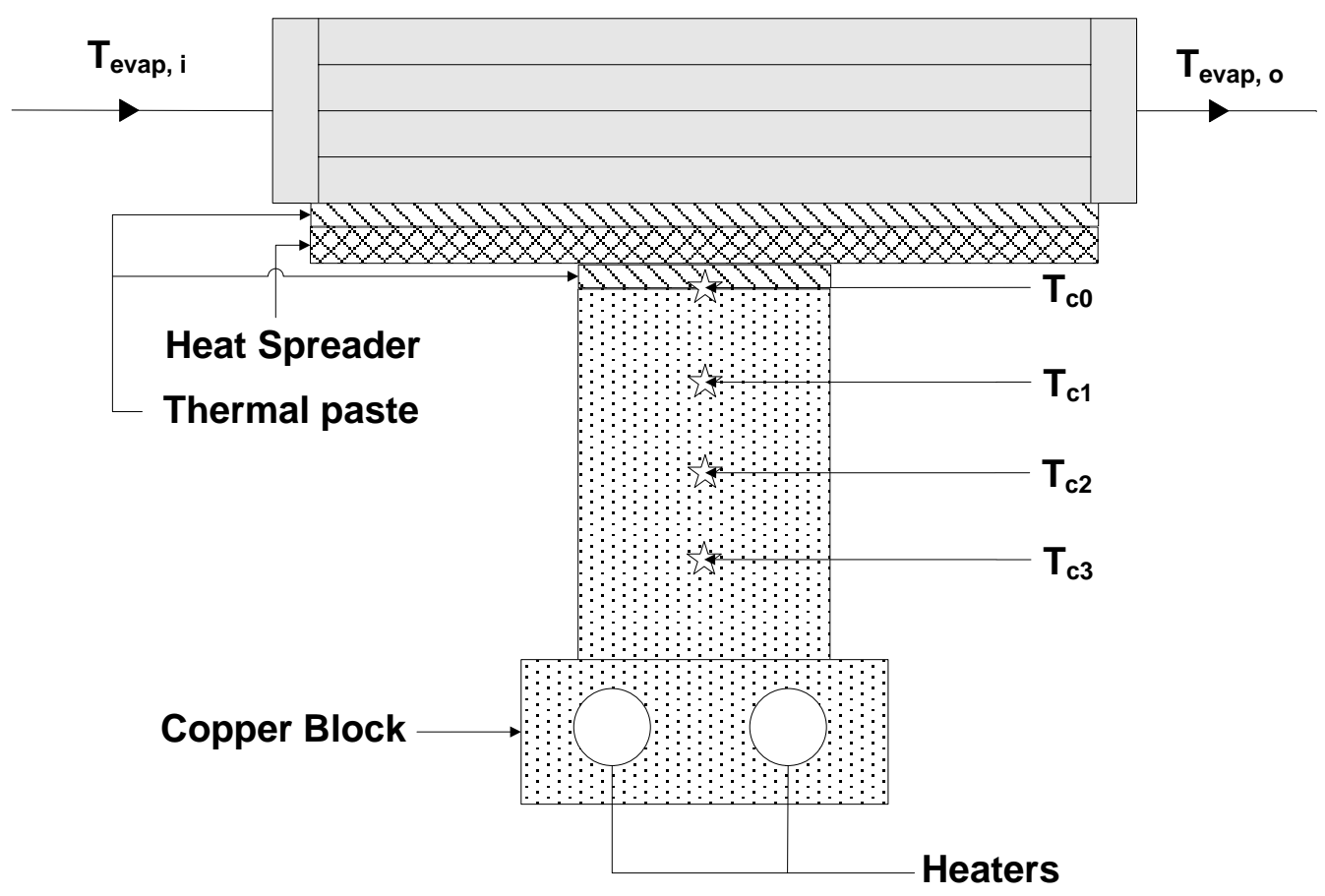

Fig. 4: Schematic of cold plate microchannel evaporator and copper cold block. 


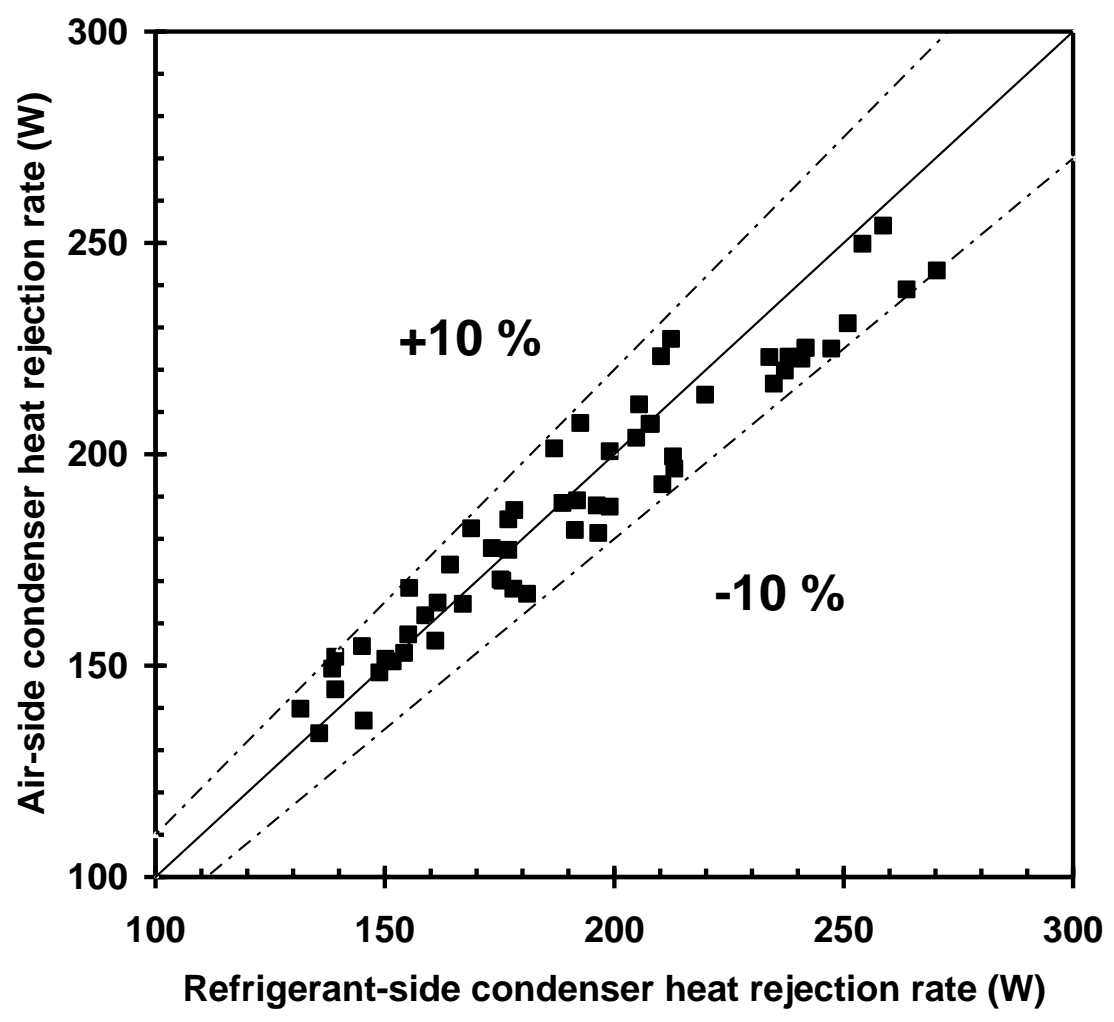

Fig. 5: Energy balance of the condenser heat rejection rate between air and refrigerant sides.

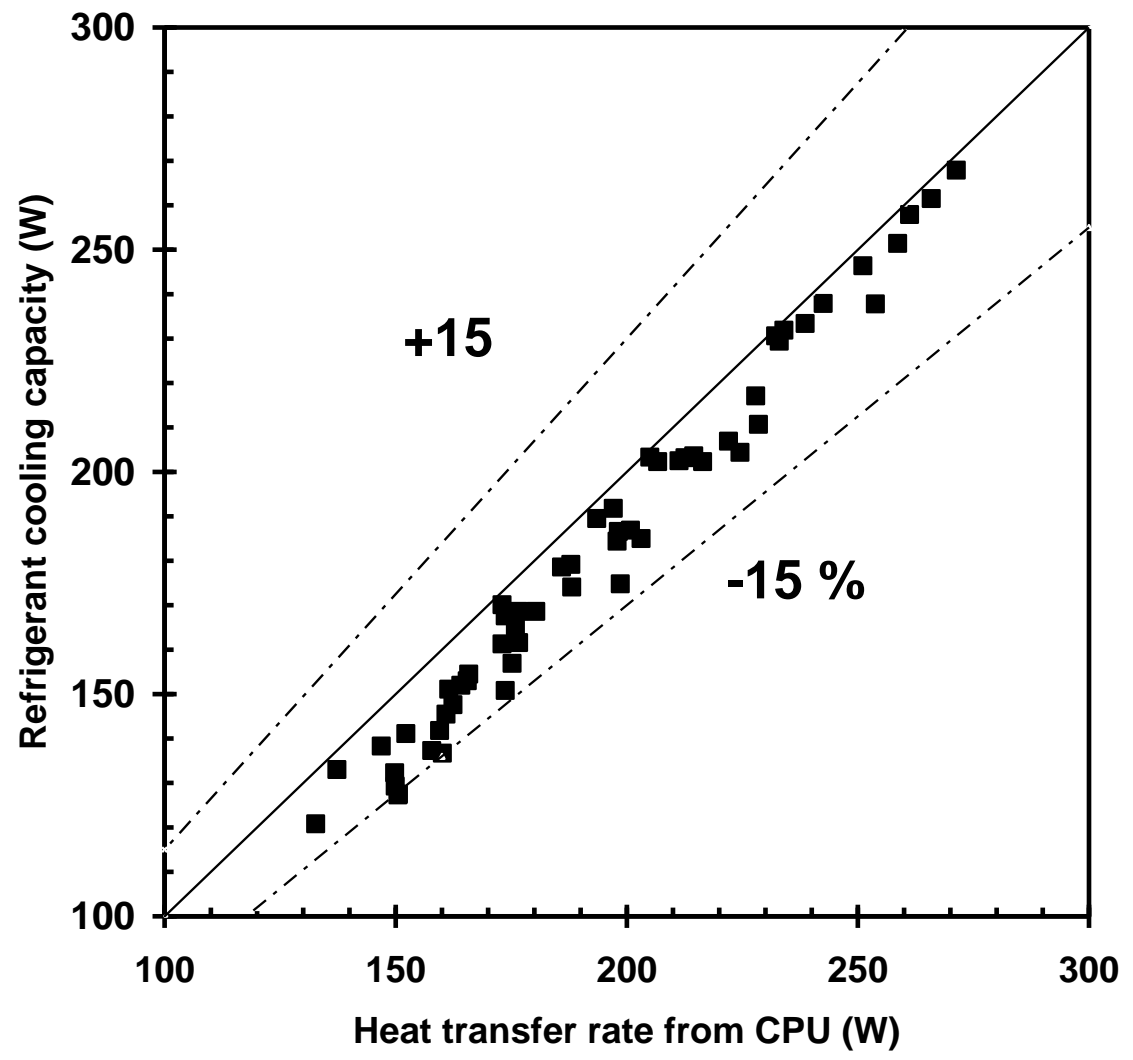

Fig. 6: Energy balance of the evaporator between refrigerant cooling capacity and heat transfer rate from CPU. 


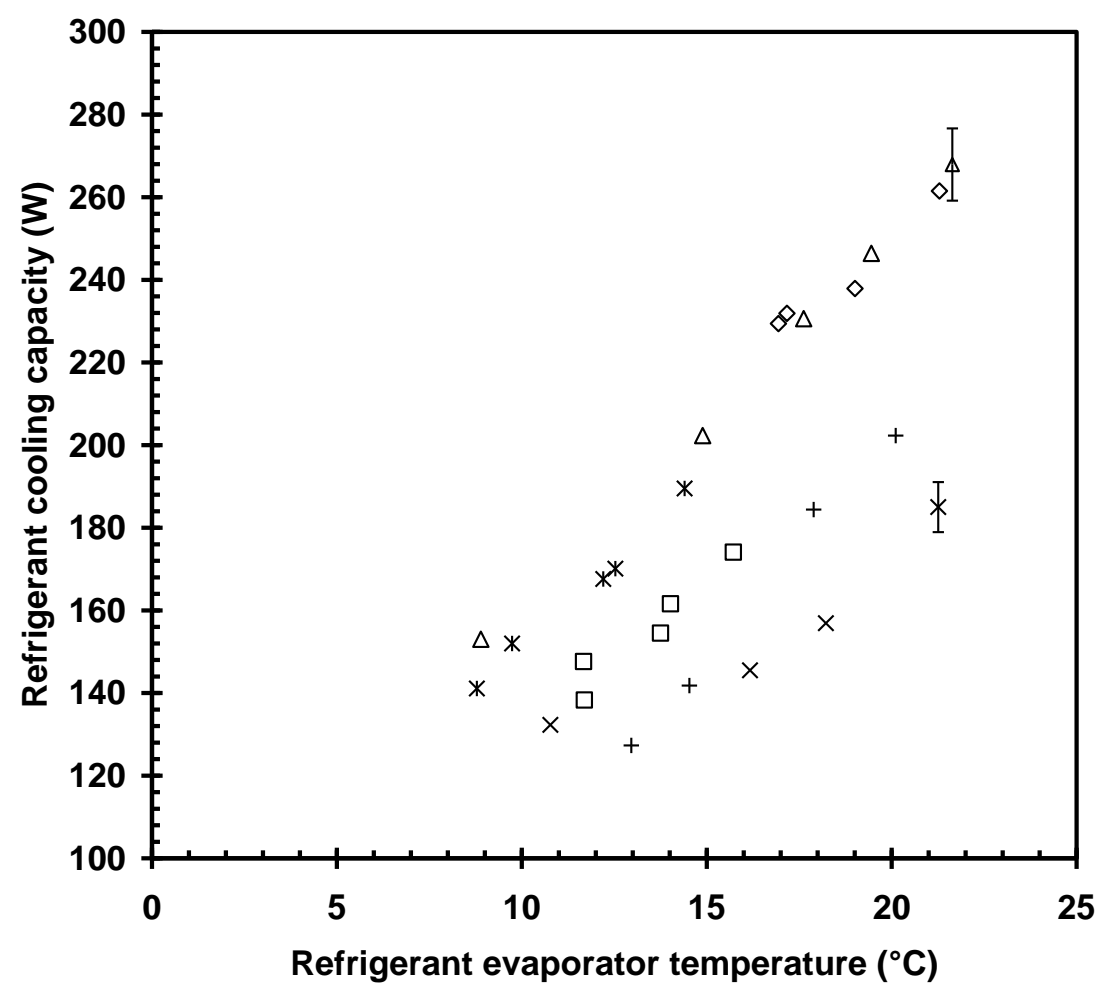

Fig. 7: Refrigerant cooling capacity versus refrigerant evaporator temperature at various condenser air inlet temperatures.

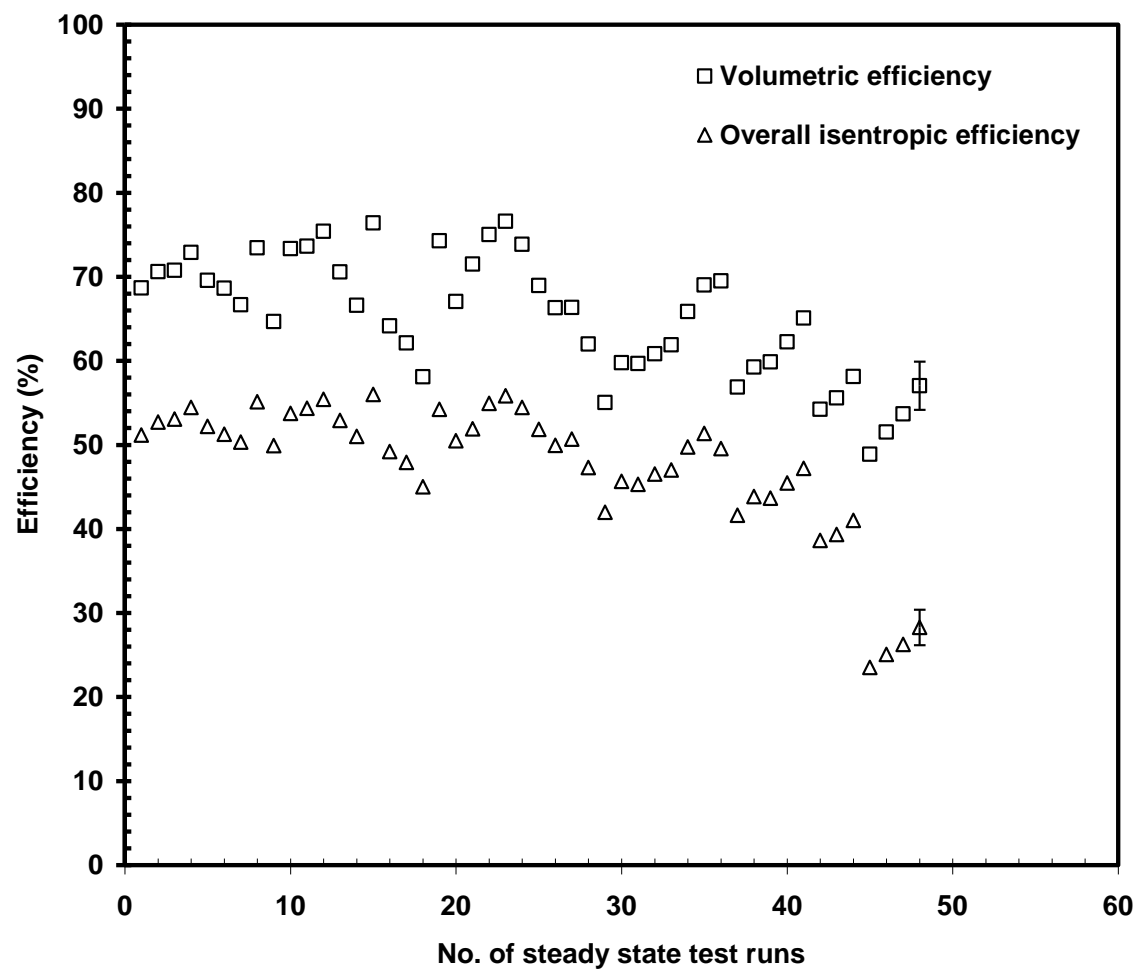

Fig. 8: Compressor efficiencies versus number of steady-state test runs. Each steady-state test had a duration of half an hour. 


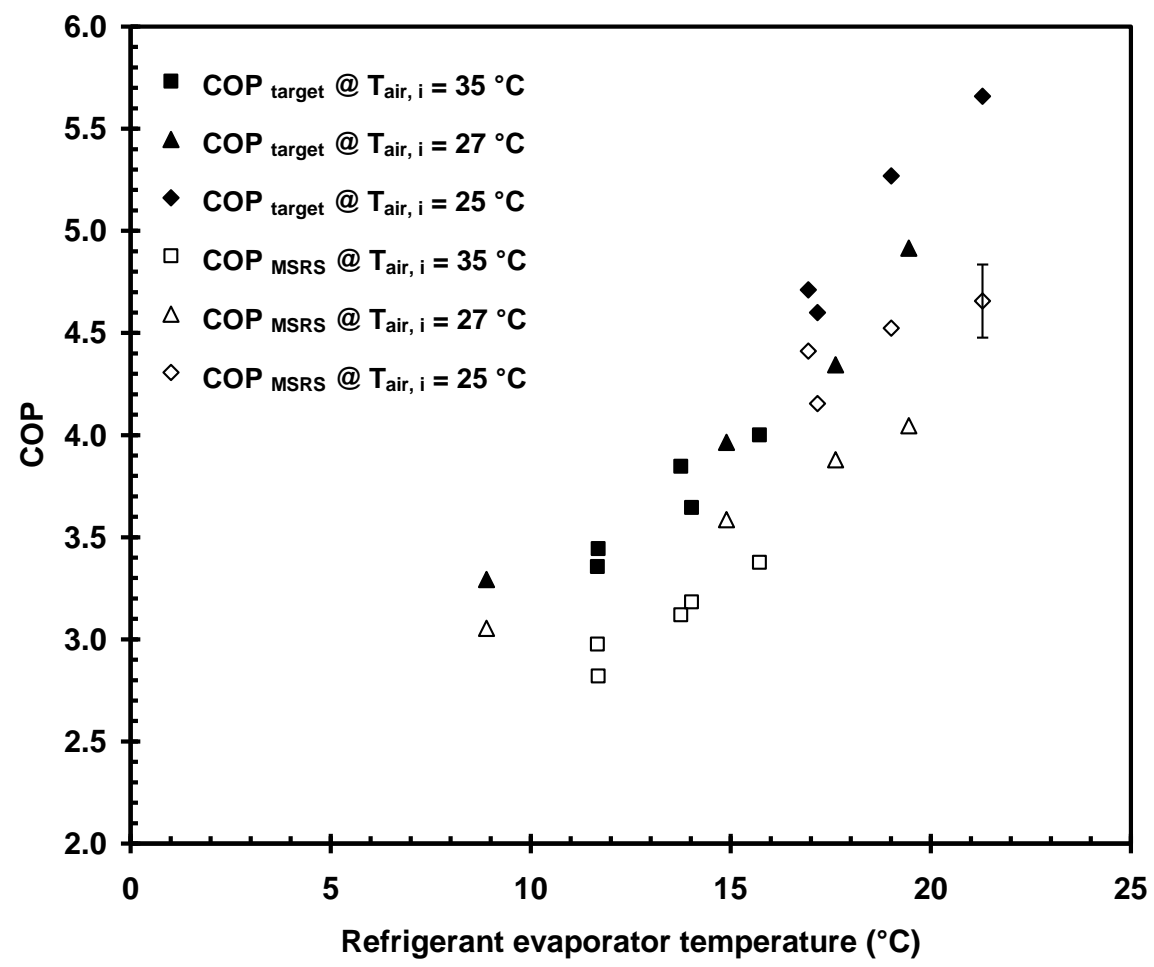

Fig. 9: COPs versus refrigerant evaporator temperature at various condenser air inlet temperatures for constant condenser air flow rate of $30 \mathrm{CFM}$.

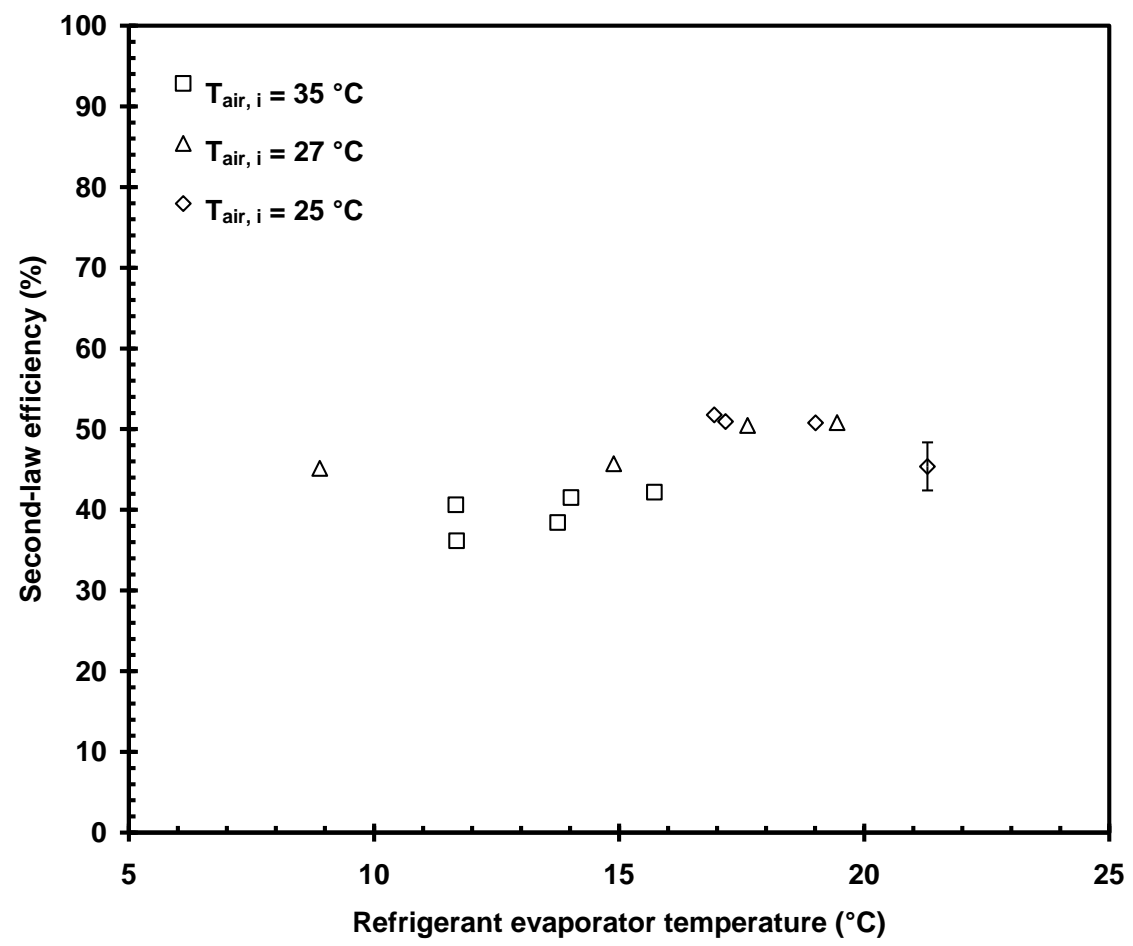

Fig. 10: Second-law efficiency of MSRS versus refrigerant evaporator temperature at various condenser air inlet temperatures. 


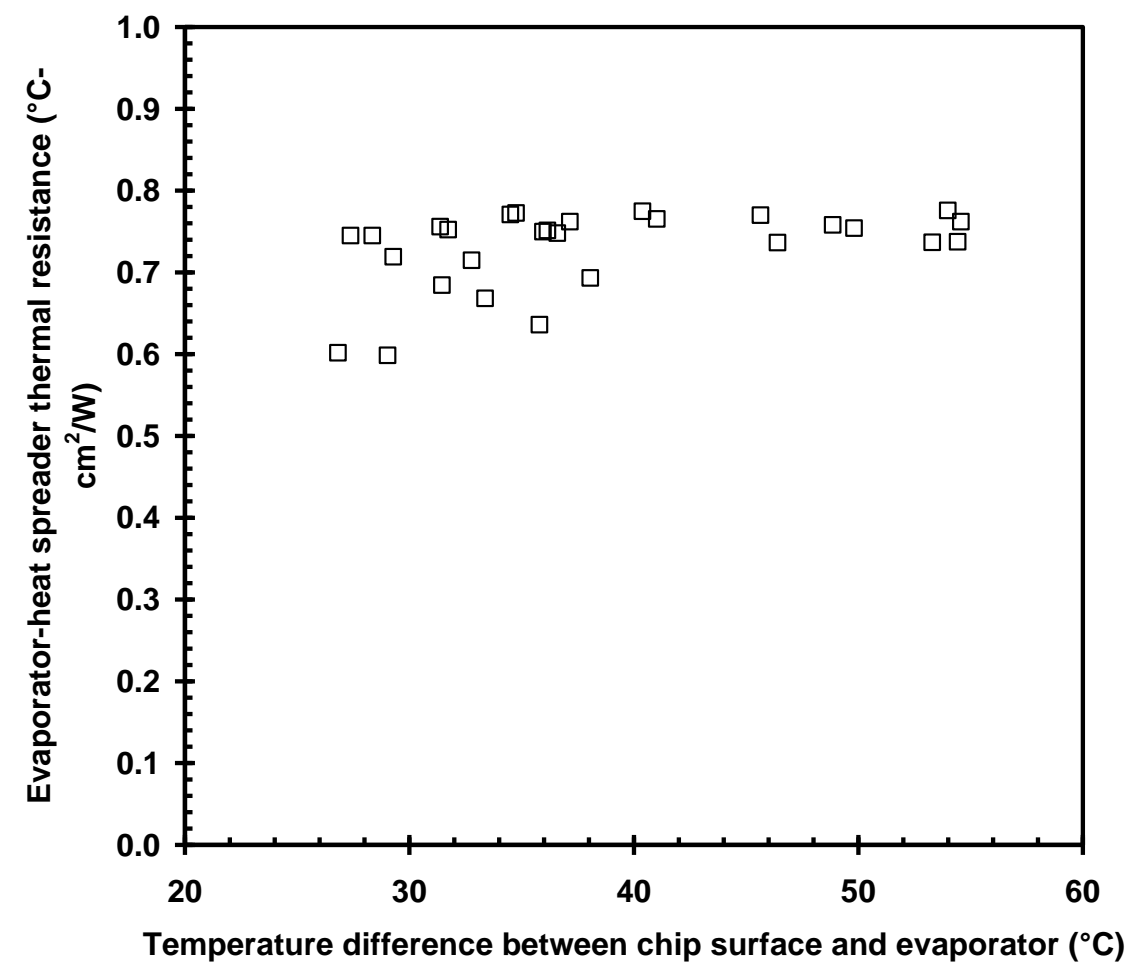

Fig. 11: Evaporator thermal resistance versus temperature difference between chip surface and refrigerant evaporator..

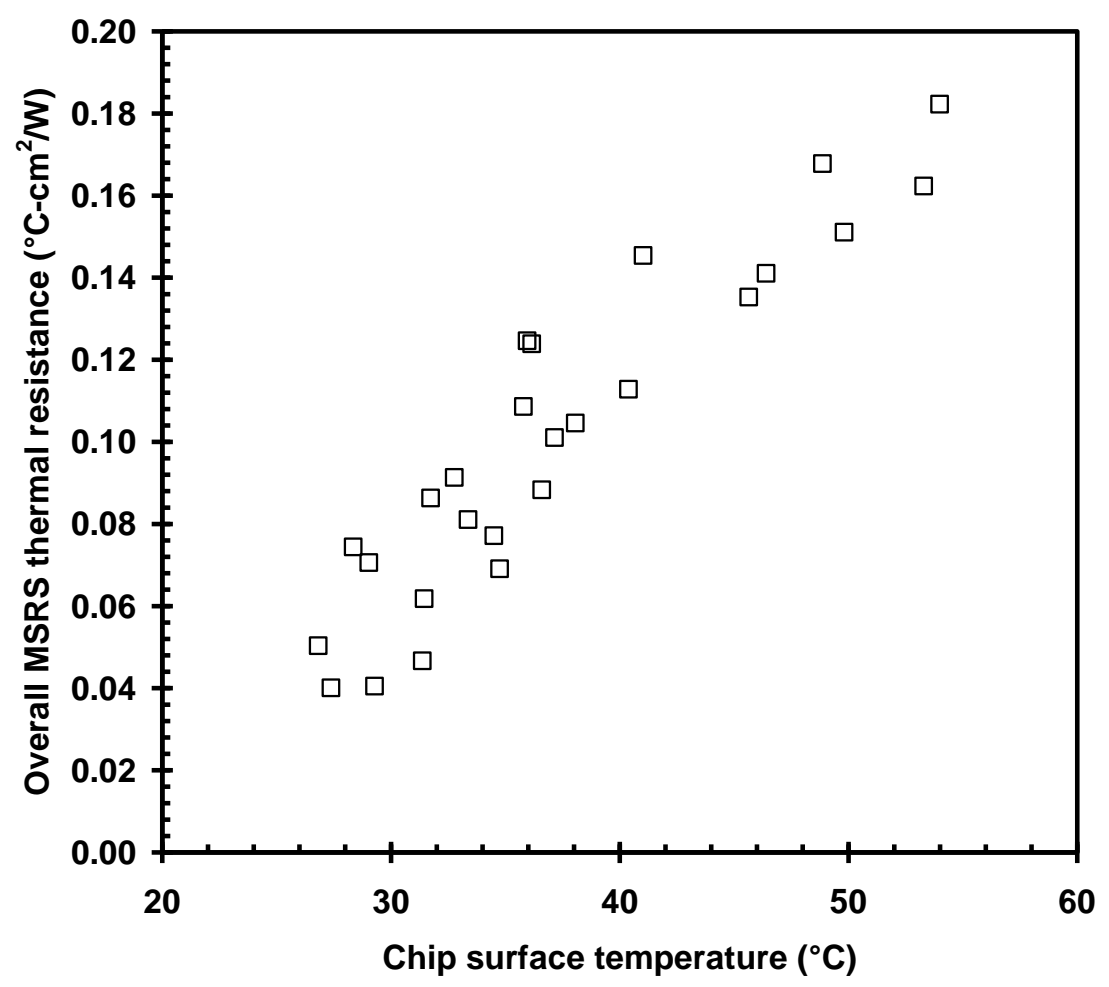

Fig. 12: Overall system thermal resistance versus chip surface temperature. 


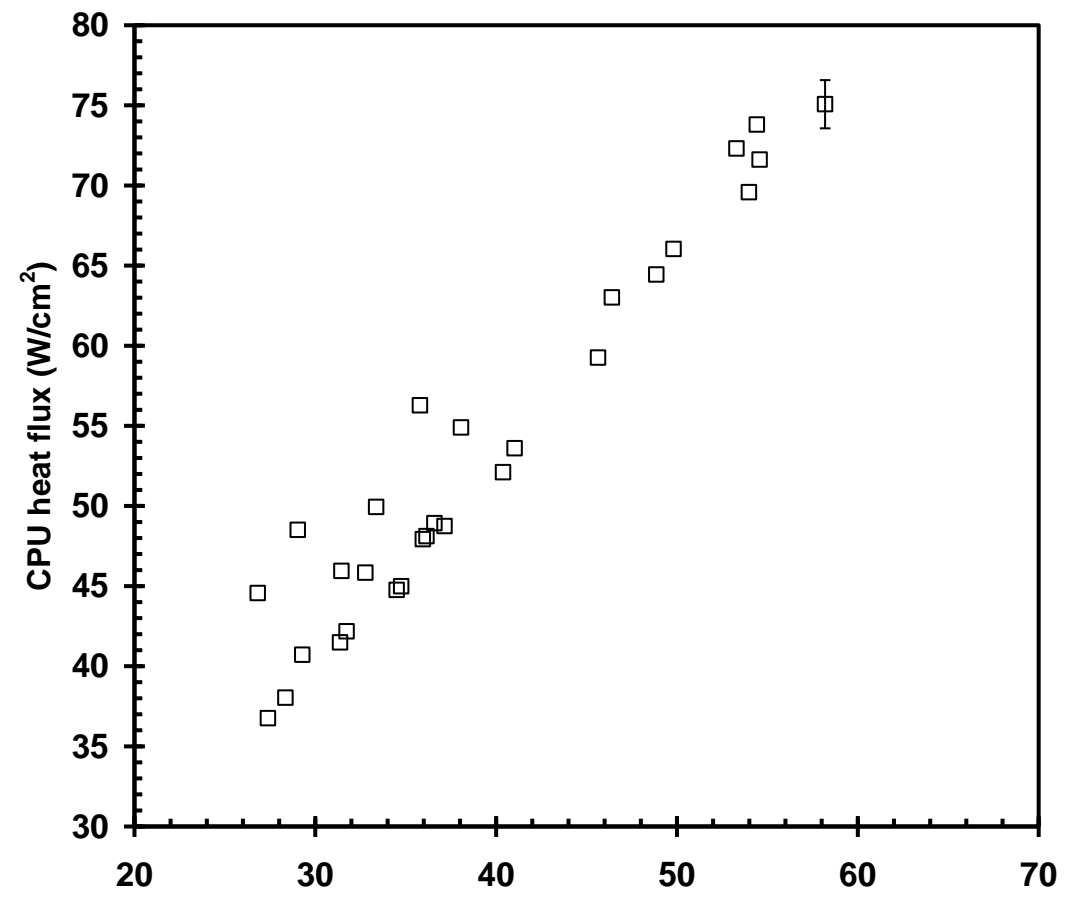

Temperature difference between chip surface and refrigerant evaporator $\left({ }^{\circ} \mathrm{C}\right)$

Fig. 13: Heat flux of simulated CPU versus temperature difference between chip surface and refrigerant evaporator temperatures. 